\title{
ON SOME CLASSES OF ANALYTIC FUNCTIONS
}

\section{KHALIDA I. NOOR and HAILA MADIFER}

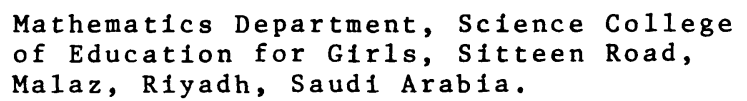

(Received April 18, 1986)

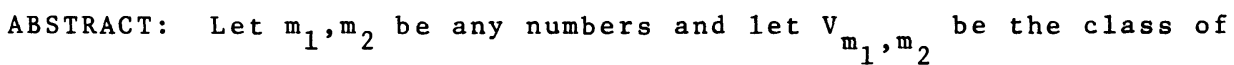
functions of analytic in the unit disc $E=\{z:|z|<1\}$ for which

$$
f^{\prime}(z)=\frac{\left(S_{1}^{\prime}(z)\right)^{m_{1}}}{\left(S_{2}^{\prime}(z)\right)^{m_{2}}}
$$

where $S_{1}$ and $S_{2}$ are analytic in $E$ with $S_{1}^{\prime}(0)=\left(S_{2}^{\prime}(0)=1\right.$. Moulis [1] gave a sufficient condition and a necessary condition on parameters $m_{1}$ and $m_{2}$ for the class $v_{m_{1}}, m_{2}$ to consist of univalent functions if $S_{1}$ and $S_{2}$ are taken to be convex univalent functions in $E$. In fact he proved that if $\mathrm{f} \varepsilon \mathrm{V}_{\mathrm{m}_{1}}, \mathrm{~m}_{2}$ where $\mathrm{s}_{1}$ and $\mathrm{s}_{2}$ are convex and $\mathrm{m}_{1}=\frac{\mathrm{k}+2}{4} \mathrm{e}^{-i \alpha}(1-\rho) \cos \alpha, \mathrm{m}_{2}=\frac{\mathrm{k}-2}{4}(1-\rho) \mathrm{e}^{-i \alpha} \cos \alpha, 2\left|\mathrm{~m}_{1}+\mathrm{m}_{2}\right| \leq 1$, then $f$ is univalent in $E$.

In this paper we consider the class $\mathrm{v}_{\mathrm{m}_{1}, \mathrm{~m}_{2}}$ in more general way and show that it contains the class of functions with bounded boundary rotation and many other classes related with 1t. Some coefficient results, arclength problem, radius of convexity and other problems are proved for certain cases. Our results generalize many previously known ones.

KEY WORDS AND PHRASES. Univalent functions, boundary rotation, radius of convexity. 1980 MATHEMATICS SUBJECT CLASSICATION CODE, 30C $32,30 \mathrm{C} 34$

1. INTRODUCTION. Let $v_{k}^{\alpha}(\rho)$ be the class of all functions $f$, analytic in $E=\{z:|z|<1\}, f^{\prime}(0)=1, f(0)=0, f^{\prime}(z) \neq$ such that for $z=r e^{1 \theta}, 0 \leq r<1$

$$
\int_{0}^{2 \pi}\left|\operatorname{Re} \frac{e^{i \alpha}\left(z f^{\prime}(z)\right)^{\prime}-\rho \cos \alpha}{1-\rho}\right| d \theta \leq k \pi \cos \alpha,
$$

where $k \geq 2,0 \leq \rho<1, \alpha \quad$ rea 1 and $|\alpha|<\frac{\pi}{2}$. 
The class $v_{k}^{\alpha}(\rho)$ has been introduced and studied by Moulis in [1]. For $\rho=0$, we obtain the class $v_{k}^{\alpha}$ introduced and studied in [2]. $\rho=0$ and $\alpha=0$ give us the well known class $v_{k}$ of functions with bounded boundary rotation first introduced and discussed by Paatero [3] and Lowner [4]. Functions in $\mathrm{v}_{\mathrm{k}}^{\alpha}$ and $\mathrm{v}_{\mathrm{k}}^{\alpha}(\rho)$ may not possess boundary rotation.

Also a class $\mathrm{T}_{\mathrm{k}}^{\alpha}(\rho)$ of analytic functions which is a generalization of $v_{k}^{\alpha}(\rho)$ has been discussed in [5]. A function $f$, analytic in $E, f(0)=0=$ $f^{\prime}(0)-1$ is in $T_{k}^{\alpha}(0)$ if for $z \in E$, there exists a function $g$ in $v_{k}^{\alpha}(\rho)$ such that

$$
\operatorname{Re} \frac{f^{\prime}(z)}{g^{\prime}(z)}>0
$$

The cases when $\rho=0$ and $\rho=0, \alpha=0$ have been discussed in [6] and [7] respective1y.

Definition 1.1

Let $m_{1}$ and $m_{2}$ be any numbers and $s_{1}$ and $s_{2}$ be analytic functions in $E$ with $S_{1}(0)=0=S_{2}(0)$ and $S_{1}^{\prime}(0)=1=S_{2}^{\prime}(0)$. Then $f \in V_{m_{1}}, m_{2}$ if and only if

$$
f^{\prime}(z)=\frac{\left(S_{1}^{\prime}(z)\right)^{m_{1}}}{\left(S_{2}^{\prime}(z)\right)^{m_{2}}}
$$

We have the following special cases.

Case A. Let $\mathrm{m}_{1}=\frac{\mathrm{k}+2}{4}, \mathrm{~m}_{2}=\frac{\mathrm{k}-2}{4}, \mathrm{k} \geq 2$ in $(1.1)$. Then

(i) $\mathrm{v}_{\mathrm{m}_{1}, \mathrm{~m}_{2}}=\mathrm{v}_{\mathrm{k}}$, the class of functions with bounded boundary rotation if $\mathrm{S}_{1}$ and $\mathrm{S}_{2}$ are convex univalent functions. This was proved by Brannan in [8].

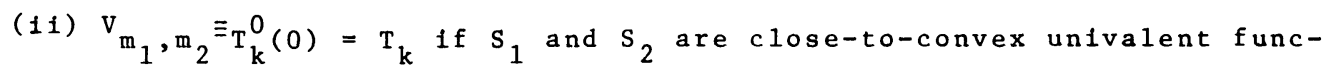
tions, see [7]. (iii) $\mathrm{v}_{\mathrm{m}_{1}}, \mathrm{~m}_{2}$ coincides with $\mathrm{v}_{\mathrm{k}}^{\alpha}$ if $\mathrm{zS}_{1}^{\prime}$ and $\mathrm{zS}_{2}^{\prime}$ are $\alpha-s p i r a 1-1 i k e$ functions.
This result is shown in [2].

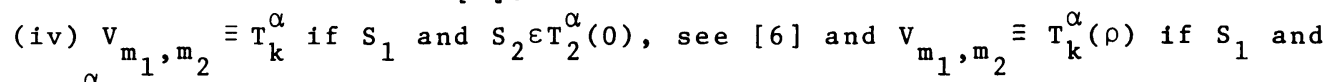
$\mathrm{S}_{2} \varepsilon \mathrm{T}_{2}^{\alpha}(\rho)$, see [5].

Case $B$. Let $S_{1}$ and $S_{2}$ be convex univalent functions in (1.1). Then we have the following subcases:

(i) If $m_{1}=\frac{k+2}{4} e^{-1 \alpha} \cos \alpha, m_{2}=\frac{k-2}{4} e^{-i \alpha} \cos \alpha$, then $f \varepsilon v_{k}^{\alpha}$ in (1.1). See [2]. (ii) If $m_{1}=\frac{4+2}{4}(1-\rho) e^{-i \alpha} \cos \alpha, m_{2}=\frac{k-2}{4}(1-\rho) e^{-i \alpha} \cos \alpha$, then $f \in v_{k}^{\alpha}(\rho)$ in relation (1.1). This is shown in [1].

2. MAIN RESULTS

We now proceed to prove the main results for the class $\mathrm{V}_{\mathrm{m}_{1}}$, $\mathrm{m}_{2}$. Wherever needed, certatin restrictions on the parameters $m_{1}$ and $m_{2}{ }_{1}$, $m_{2}{ }^{2}$ an analytic functions $S_{1}$ and $S_{2}$ will be imposed.

\section{Theorem 2.1}

Let $\mathrm{f} \varepsilon \mathrm{V}_{\mathrm{m}_{1}, \mathrm{~m}_{2}}$ such that 


$$
f^{\prime}(z)=\frac{\left(S_{1}^{\prime}(z)\right)^{m_{1}}}{\left(S^{\prime}{ }_{2}(z)\right)^{m_{2}}}
$$

where $S_{1}$ and $S_{2}$ are convex univalent in $E$. Let

$$
I_{\lambda}(r)=\frac{1}{2 \pi} \int_{0}^{2 \pi}\left|f^{\prime}\left(r e^{i \theta}\right)\right|^{\lambda} d \theta \text {. }
$$

where $0 \leq \mathrm{r}<1$ and $2 \mathrm{~m}_{1} \lambda>1 ; \mathrm{m}_{1}, \mathrm{~m}_{2}>0$

Then

$$
\lim _{\mathrm{r} \rightarrow 1} \sup (1-\mathrm{r})^{2 \mathrm{~m}_{1} \lambda-1} \mathrm{I}_{\lambda}(\mathrm{r}) \leq \mathrm{A}\left(\mathrm{m}_{1}, \mathrm{~m}_{2}, \lambda\right)
$$

where

$$
A\left(m_{1}, m_{2}, \lambda\right)=\frac{2^{2 m_{2} \lambda} \Gamma\left(m_{1} \lambda+\frac{1}{2}\right)}{\pi^{\frac{1}{2}}\left(2 m_{1} \lambda-1\right) \Gamma\left(m_{1} \lambda\right)}
$$

Proof

$$
I_{\lambda}(r)=\frac{1}{2 \pi} \int_{0}^{2 \pi\left|s_{1}^{\prime}(z)\right|^{m_{1} \lambda}} \frac{\left|s_{2}^{\prime}(z)\right|^{m_{2}}}{\mid c} d \theta, s_{1}, s_{2} \text { are convex functions, } m_{1}, m_{2}>0 .
$$

Then $\left|s_{2}^{\prime}(z)\right| \geq \frac{1}{(1+r)^{2}}$ by the distortion theorems for convex functions [9] and $S_{i}$ is subdrathate to $(1-z)^{-2}$ in $E$. Consequently

$$
I_{\lambda}(r) \leq \frac{1}{2 \pi}(1+r)^{2 m_{2} \lambda} \int_{0}^{2 \pi} \frac{1}{\left|1-r e^{1 \theta}\right|^{2 m_{1} \lambda}} d \theta=(1+r)^{2 m_{2} \lambda} J_{2 m_{1}} \lambda^{(r)} \text {, say }
$$

Now it has been shown by Pommerenke in [10] that

$$
\begin{aligned}
J_{p}(r) & \simeq \frac{\Gamma(p-1)}{2^{p-1} \Gamma^{2}(p)} \frac{1}{(1-r)^{p-1}}, p>1, \quad r \rightarrow 1 \\
& =\frac{\Gamma\left(\frac{1}{2} p+\frac{1}{2}\right)}{\pi^{\frac{1}{2}}(p-1) \Gamma\left(\frac{1}{2} p\right)} \cdot \frac{1}{(1-r)^{p-1}}
\end{aligned}
$$

using the recurrence and duplication formulae for the Gama function. Substitution of $(2.3)$ in $(2.2)$ completes the proof.

Corollary 2.1

$$
\text { Let } m_{1}=\frac{k+2}{4}, m_{2}=\frac{k-2}{4} \text {. Then } f \in V_{k}
$$

and

$$
\begin{aligned}
& \lim _{r \rightarrow 1} \operatorname{Sup}(1-r)^{\left(\frac{1}{2} k-1\right) \lambda-1} I_{\lambda}(r) \leq A(k, \lambda), \text { where } \\
& A(k, \lambda)=\frac{2^{\left(\frac{1}{2} k-1\right) \lambda} \Gamma\left(\frac{1}{4} k \lambda+\frac{1}{2} \lambda+\frac{1}{2}\right)}{\pi^{\frac{1}{2}}\left(\frac{1}{2} k \lambda+\lambda-1\right) \Gamma\left(\frac{1}{4} k \lambda+\frac{1}{2} \lambda\right)}
\end{aligned}
$$


This result was proved in [8].

Theorem 2.2

Let $f \in V_{m_{1}}, m_{2}$, and $s_{1}, S_{2}$ be convex functions. Let $L(r)$ denote the length of the arc $f(|z|=r)$ given by the formula for $z=r e^{i \theta}$.

$$
L(r)=\int_{0}^{2 \pi}\left|z f^{\prime}(z)\right| d \theta
$$

Then, for $m_{1}>\frac{1}{2}, m_{2}>0$, we have

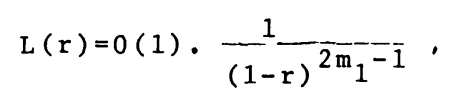

where $O(1)$ is a constant depending only on $\mathrm{m}_{1}$ and $\mathrm{m}_{2}$.

The proof follows immediately from Theorem 2.1 by taking $\lambda=1$.

From Theorem 2.1 and the standard inequality [9,p.11].

$$
\left|a_{n}\right|<\frac{e}{n} I_{1}\left(1-\frac{1}{2}\right) \text {, }
$$

\section{we have the following.}

Theorem 2.3

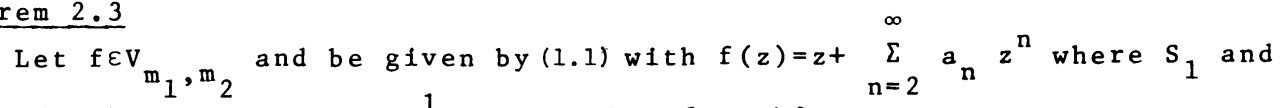
$\mathrm{s}_{2}$ in (2.1) are convex, $\mathrm{m}_{1}>\frac{1}{2}, \mathrm{~m}_{2}>0$. Then for $n \geq 2$

$$
\lim _{n \rightarrow \infty} \operatorname{Sup} n^{2-2 m_{1}} a_{n} \mid \leq \frac{e^{2 m_{2}} \Gamma\left(m_{1}+\frac{1}{2}\right)}{\pi^{\frac{1}{2}}\left(2 m_{1}-1\right) \Gamma\left(m_{1}\right)}
$$

\section{Corollary 2.2}

If $m_{1}=\frac{k+2}{4}, m_{2}=\frac{k-2}{4}$ in Theorem 2.3 then $f \in v_{k}$ and

$\lim _{n \rightarrow \infty} \sup \left[n^{1-\frac{1}{2} k}\left|a_{n}\right|\right] \leq \frac{e 2^{\frac{1}{2} k} \Gamma\left(\frac{k}{4}+1\right)}{\pi^{\frac{1}{2}}(k) \Gamma\left(\frac{k}{4}+\frac{1}{2}\right)}$

This result was proved in [8].

Theorem 2.4

Let $\mathrm{f} \varepsilon \mathrm{V}_{\mathrm{m}_{1}}, \mathrm{~m}_{2}$ with $\mathrm{s}_{1}$ and $\mathrm{s}_{2}$ convex and $\mathrm{m}_{1}>1, \mathrm{~m}_{2}>0$. Let $\mathrm{f}$ be given by $f(z) \quad z+\sum_{n=2}^{\infty} a_{n} z^{n}$. Then for $n \geq 1$

$$
|| a_{n+1}|-| a_{n}|| \leq C\left(m_{1}, m_{2}\right) n^{2 m_{1}-3},
$$

where $C\left(m_{1}, m_{2}\right)$ is a constant depending on $1 y$ on $m_{1}$ and $m_{2}$.

Proof

$$
\begin{aligned}
& \text { For } z_{1} \varepsilon E \text { and } n \geq 1 \text {, we have } \\
& \begin{aligned}
\left|(n+1) z_{1} a_{n+1}-n a_{n}\right| & =\frac{1}{2 \pi r^{n+1}} \int_{0}^{2 \pi}\left|z-z_{1}\right|\left|z f^{\prime}(z)\right| d \theta, z=r e^{1 \theta} \\
& =\frac{1}{2 \pi r^{n}} \int_{0}^{2 \pi}\left|z-z_{1}\right| \frac{\left|s_{1}^{\prime}(z)\right|^{m}}{\left|s^{\prime}{ }_{2}(z)\right|^{m}} d \theta
\end{aligned}
\end{aligned}
$$


It is known [9] that for convex univalent functions $\mathrm{s}_{2}$

$$
\left|S_{2}^{\prime}(z)\right| \geq \frac{1}{(1+r)^{2}}
$$

Also, by a result of Golusin [11], there exists a $z_{1} \varepsilon E$ with $\left|z_{1}\right|=r$ such that for all z, $|z|=r$

$$
\left|z-z_{1}\right|\left|S_{1}^{*}(z)\right| \leq \frac{2}{1-r^{2}}
$$

where $S_{1}^{*}(z)=z S_{1}^{\prime}(z)$ is univalent

Using $(2.5)$ and $(2.6),(2.4)$ becomes

$$
\begin{gathered}
\left|(n+1) z_{1} a_{n+1}-n a_{n}\right| \leq \frac{(1+r)^{2 m}}{2 \pi r^{n-1}}\left(\frac{2 r^{2}}{1-r^{2}}\right) \int_{0}^{2 \pi}\left|S_{1}^{\prime}(z)\right|^{m_{1}-1} d \theta \\
\leq \frac{(1+r)^{2 m_{2}-1}}{\pi r^{n-3}} \cdot \frac{1}{(1-r)^{2 m_{1}-2}}
\end{gathered}
$$

where we have used subordination for the function $s_{1}$.

putting $\left|z_{1}\right|=r, r=\frac{n}{n+1}$, we obtain the required result.

Coro11ary 2.3

Taking $\mathrm{m}_{1}=\frac{\mathrm{k}+2}{4}, \mathrm{~m}_{2}=\frac{\mathrm{k}-2}{4}, \mathrm{k} \geq 2$, we obtain $f \in v_{k}$ and $\left\|a_{n+1}|-| a_{n}\right\| \leq c(k) n^{\frac{k}{2}-2}$, where $c(k)$ is a constant depending only on $k$.

Now we give the radius of convexity problem for the class $v_{m_{1}}, m_{2}$ where the functions $S_{1}$ and $S_{2}$ are in $v_{k}$.

Theorem 2.5

Let $\mathrm{f} \varepsilon \mathrm{V}_{\mathrm{m}_{1}}, \mathrm{~m}_{2} \mathrm{such}$ that

$$
f^{\prime}(z)=\frac{\left(S_{1}^{\prime}(z)\right)^{m_{1}}}{\left(S_{2}^{\prime}(z)\right)^{m_{2}}},
$$

where $\mathrm{s}_{1}, \mathrm{~S}_{2} \varepsilon \mathrm{V}_{\mathrm{k}}$ and $\mathrm{m}_{1}, \mathrm{~m}_{2} \geq 0$ and real. Then $\mathrm{f}$ is convex for $|z|<\mathrm{r}$ where $r$ is the least positive root of

$$
\left[1+m_{2}\left(1-\frac{k}{2}\right)\right]-k\left(m_{1}+m_{2}\right) r+\left[2 m_{1}-m_{2}\left(1+\frac{k}{2}\right)-1\right] r^{2}=0
$$

Proof

From definition it easily follows that

$$
\frac{\left(z f^{\prime}(z)\right)^{\prime}}{f^{\prime}(z)}=m_{1} \frac{\left(z S_{1}^{\prime}(z)\right)^{\prime}}{S_{1}^{\prime}(z)}-m_{2} \frac{\left(z S_{2}^{\prime}(z)\right)^{\prime}}{s_{2}^{\prime}(z)}+\left(1-m_{1}+m_{2}\right)
$$

Now, for $s_{1} \varepsilon V_{k}$ it is known [12] that

$$
\operatorname{Re} \frac{\left(z S_{1}^{\prime}(z)\right)^{\prime}}{S_{1}^{\prime}(z)} \geq \frac{1-k r+r^{2}}{1-r^{2}}
$$


Also, by the Paatero representation theorem [3] we have, for $S_{2} \varepsilon V_{k}$, $\frac{\left(z S_{2}^{\prime}(z)\right)^{\prime}}{S_{2}^{\prime}(z)}=\frac{k+2}{4} h_{1}(z)-\frac{k-2}{4} h_{2}(z), \operatorname{Re} h_{i}(z) \geq 0, i=1,2$, and $h_{i}(0)=1$ so that

$$
\operatorname{Re} \frac{\left(z S_{2}^{\prime}(z)\right)^{\prime}}{S_{2}^{\prime}(z)} \leq\left|\frac{\left(z S_{2}^{\prime}(z)\right)^{\prime}}{S_{2}^{\prime}(z)}\right| \leq \frac{k}{2} \frac{1+r}{1-r}
$$

Thus, using $(2.8)$ and $(2.9)$, we have

$$
\operatorname{Re} \frac{\left(z f^{\prime}(z)\right)^{\prime}}{f^{\prime}(z)} \leq \frac{\left[1+m_{2}\left(1-\frac{k}{2}\right)\right]-k\left(m_{1}+m_{2}\right) r+\left[2 m_{1}-m_{2}\left(1+\frac{k}{2}\right)-1\right] r^{2}}{1-r^{2}}
$$

and this gives us the required result.

Corollary 2.4

If $k=2$, then $S_{1}, S_{2} \varepsilon V_{2}=C$, the class of convex functions and equation (2.7) reduces to

$$
1-2\left(m_{1}+m_{2}\right) r+\left(2 m_{1}-2 m_{2}-1\right) r^{2}=0
$$

and in this case if $m_{1}=\frac{k+2}{4}, m_{2}=\frac{k-2}{4}$ then $v_{m_{1}, m_{2}}$ reduces to $v_{k}$ and equation (2.7) reduces to the known result

$$
1-k r+r^{2}=0
$$

which was given in[12].

Corol1ary 2.5

If $\mathrm{m}_{1}=\alpha>0, \mathrm{~m}_{2}=0$, then $\mathrm{f}$ is convex for $|z|<r$, where $r$ is the least positive root of

$$
1-k \alpha r+(2 \alpha-1) r^{2}=0
$$

This result has been proved in [13].

Theorem 2.6

$$
\text { Let } f_{\varepsilon \mathrm{V}_{\mathrm{m}_{1}}, \mathrm{~m}_{2} \text { such that }} \mathrm{f}^{\prime}(\mathrm{z})=\frac{\left(\mathrm{S}_{1}^{\prime}(\mathrm{z})\right)^{\mathrm{m}_{1}}}{\left(\mathrm{~S}_{2}^{\prime}(\mathrm{z})\right)^{\mathrm{m}}},
$$

and $s_{1}, s_{2} \varepsilon v_{k}, m_{1}, m_{2} \geq 0, m_{1}-m_{2} \leq 1$.

Then $f \in V_{k^{\prime}}$, where $k^{\prime}=\left\{m_{1}(k-2)+m_{2}(k+2)+2\right\}$

From the above result, we deduce the following:

(i) If $\mathrm{s}_{1}, \mathrm{~s}_{2} \varepsilon \mathrm{V}_{2}$, then $\mathrm{f} \varepsilon \mathrm{V}_{4 \mathrm{~m}_{2}+2}$ and in this case if $\mathrm{m}_{1}=\frac{\mathrm{k}+2}{4}, \mathrm{~m}_{2}=\frac{\mathrm{k}-2}{4}$, we have the well known result [8] that $f \in V_{k}$.

(ii) If $\mathrm{m}_{1}=\alpha, \mathrm{m}_{2}=0, \quad 0 \leq \alpha \leq 1$, then $\mathrm{f} \varepsilon \mathrm{V}_{\alpha(\mathrm{k}-2)+2}$. 


\section{REFERENCES}

1. MOULIS, E.J. Generalization of the Robertson functions, Pacific J. Math., 81 (1979), 169-74.

2. MOULIS, E.J. A generalization of univalent functions with bounded boundary rotation, Trans. Amer. Math. Soc. 174 (1972): 369-381.

3. PAATERO, V. Uber die Konforme Abbildungen von Gebieten deren Rander von beschrankter Drehung sind, Ann. Acad. Sci. Fenn. Ser. A. 33 no.9 (1931).

4. LOWNER, K. Untersuchungen uber die verzerrung die Konformen Abbildungen des Einheitschreises $|z|<1$, die durch Funktionen, mit nicht werschwindender Ableifert geleifert werden, Leip. Ber. 69 (1917),

5. NOOR,K.I. and AL-DIHAN N. On a generalization of functions with bounded boundary rotation, to appear.

6. NOOR,K.I. and AL-OBOUDI, M. A generalization of a class of functions of bounded boundary rotation, Expo. Math. 1 (1983), 279-281.

7. NOOR,K.I. On a generalization of close-to-convexity. Int. J. Math. and Math.Sci. $\underline{6}$ (1983), 327-334。

8. BRANNAN D.A. On functions of bounded boundary rotation, Proc. Edin. Math. Soc., 2 $(1968 / 69), 339-347$.

9. HAYMAN, W.K. Multivalent functions, Cambridge University Press, 1958.

10. POMMERENKE $\mathrm{CH}$. On the coefficients of close-to-convex functions, Michigan Math. J. 9 (1962), 259-269.

11. GOLUSIN, G.M. On distortion theorems and coefficients of univalent functions, Mat. Sb. 19(1946): 183-203.

12. ROBERTSON,M.S. Coefficients of functions with bounded boundary rotation, Canadian J. Math. XX1 (1969), 1477-1482.

13. NOOR, K.I. and MADIFER H. Some radius of convexity problems for certain classes of analytic functions, Int. J. Math. \& Math. Sc1., 7 (1984), 713-718. 


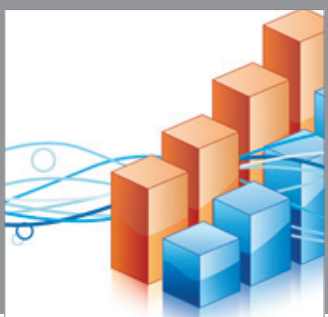

Advances in

Operations Research

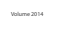

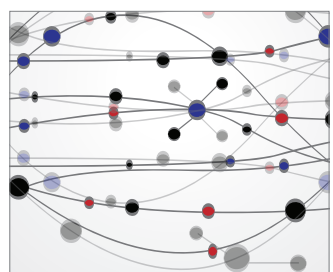

\section{The Scientific} World Journal
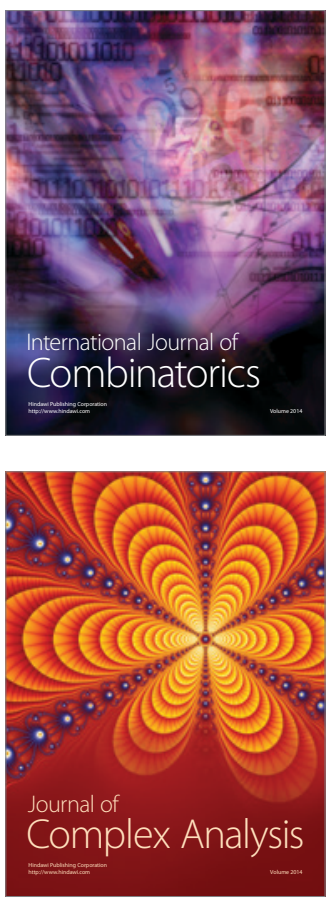

International Journal of

Mathematics and

Mathematical

Sciences
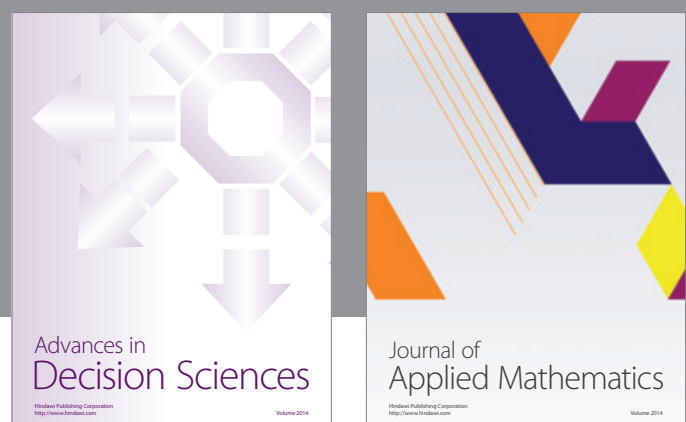

Journal of

Applied Mathematics
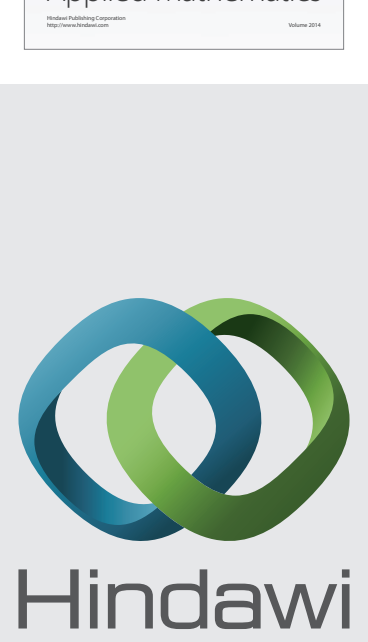

Submit your manuscripts at http://www.hindawi.com
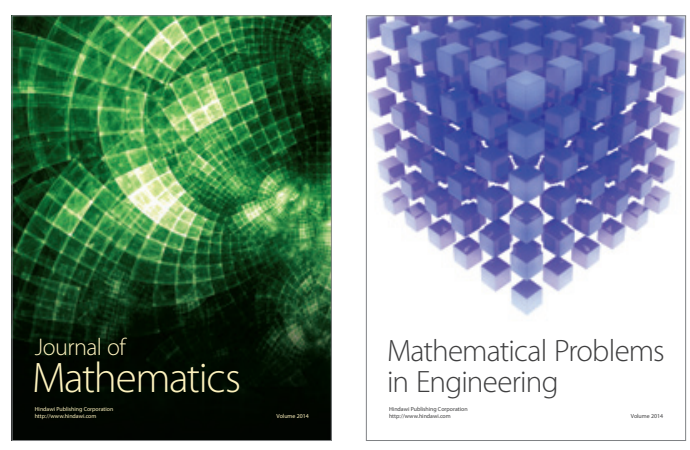

Mathematical Problems in Engineering
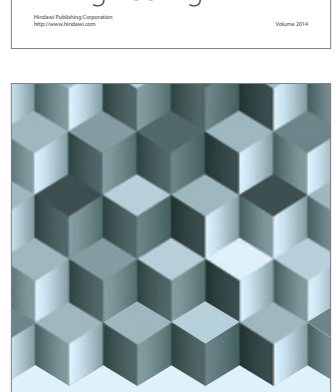

Journal of

Function Spaces
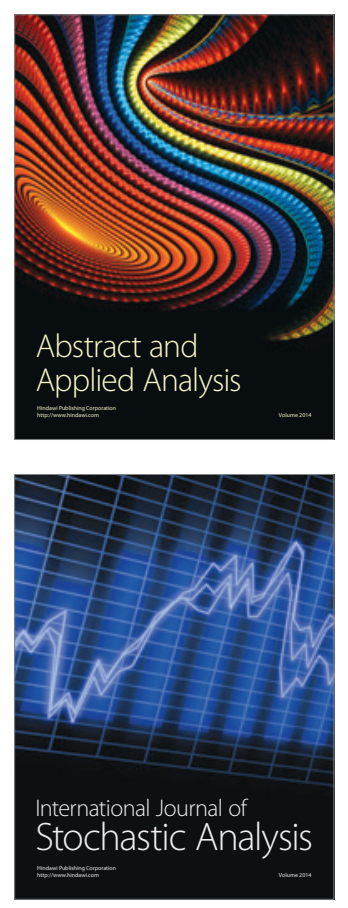

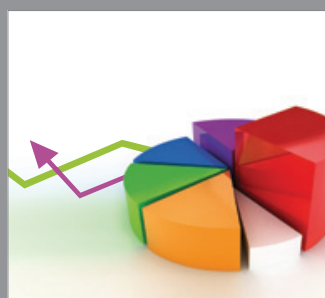

ournal of

Probability and Statistics

Promensencen
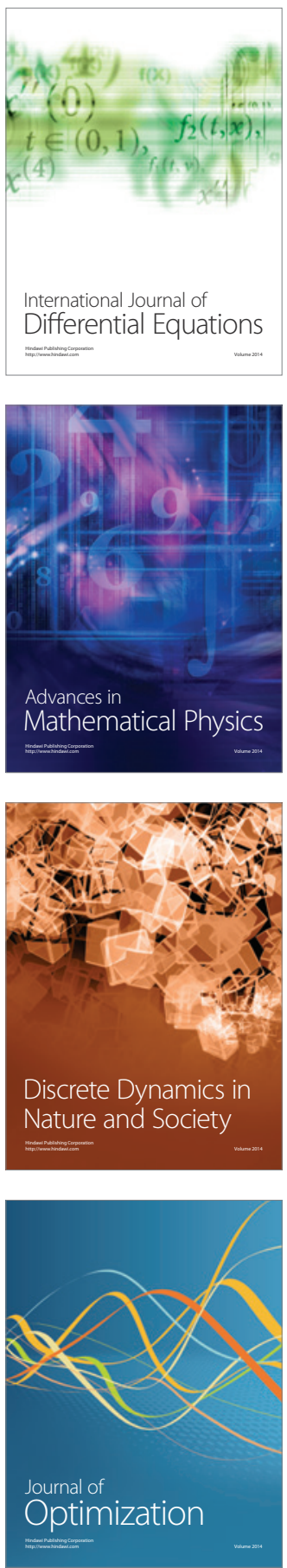